\title{
Effect of storage temperature of insulin on pharmacokinetics and pharmacodynamics of insulin mixtures injected subcutaneously in subjects with Type 1 (insulin-dependent) diabetes mellitus
}

\author{
G. Perriello, E.Torlone, S. Di Santo, C.Fanelli, P. De Feo, F.Santeusanio, P. Brunetti and G. B. Bolli \\ Istituto di Patologia Speciale Medica e Metodologia Clinica dell'Università di Perugia, Italy
}

\begin{abstract}
Summary. These studies were undertaken to assess the influence of storage temperature of insulin vials on pharmacokinetics and pharmacodynamics of a mixture of lente insulin (Monotard HM) and regular insulin (Actrapid HM) injected subcutaneously. Seven subjects with Type 1 (insulin-dependent) diabetes mellitus were studied twice after overnight normalization of plasma glucose. A mixture of lente insulin $(0.22 \mathrm{U} / \mathrm{kg})$ and regular insulin $(0.11 \mathrm{U} / \mathrm{kg})$ was prepared from insulin vials kept either refrigerated $\left(\sim 4^{\circ} \mathrm{C}\right)$ or at room temperature $\left(\sim 18^{\circ} \mathrm{C}\right)$ and injected subcutaneoulsy (abdomen). Euglycaemia was maintained for the following $16 \mathrm{~h}$ by glucose infusion at variable rate. With refrigerated insulin, the plasma free insulin peak was greater $(53 \pm 5$ versus $45 \pm 6 \mathrm{mU} / \mathrm{l})$ and occurred earlier $(2.5 \pm 0.2$ versus $6 \pm 0.3 \mathrm{~h}$ ), and the glucose infusion rate showed a greater $(16.5 \pm 1.2$ versus $\left.14.5 \pm 0.9 \mu \mathrm{mol} \cdot \mathrm{kg}^{-1} \cdot \mathrm{min}^{-1}\right)$ and earlier peak $(3.2 \pm 0.2$ versus $6 \pm 0.4 \mathrm{~h})$ as compared to that occurring with
\end{abstract}

the non-refrigerated insulin $(p<0.05)$. However, $6 \mathrm{~h}$ after insulin injection, both plasma free insulin and glucose infusion rate were $30 \%$ lower with the mixture of refrigerated as compared to that of non-refrigerated insulin $(p<0.05)$. In contrast, when NPH-insulin (Protaphane HM) was mixed with regular insulin and injected in 4 out of the 7 diabetic patients, the storage temperature of insulin vials had no effect on the pharmacokinetics and pharmacodynamics of the mixture. Thus, the storage temperature of insulin vials profoundly influences the effects of the mixture lente/regular insulin, but does not affect the pharmacokinetics and pharmacodynamics of the mixture NPH/regular insulin.

Key words: Insulin pharmacokinetics, insulin pharmacodynamics, insulin mixtures, glucose clamp, insulin absorption, regular insulin, lente insulin, NPH insulin.
Several studies have recently shown that subcutaneous injections of mixtures of regular and lente insulin [1-7], or ultralente insulin [8] in man result in a partial loss of activity of the rapid component. Preprandial injections of these mixtures in subjects with Type 1 (insulin-dependent) and Type 2 (non-insulin-dependent) diabetes mellitus result in an exaggerated postprandial hyperglycaemia [9-11]. In contrast, when regular insulin is mixed with NPH insulin, the action profile of the fast component is maintained $[2,4,5,7,12]$. Despite various concerns that injections of mixtures of lente and regular insulin may lead to erratic pharmacokinetics of insulin [13, 14], mixing regular and lente insulin nevertheless remains a common practice in subjects with Type 1 diabetes mellitus. Recently we observed in pilot experiments that the activity of the fast component of a mixture of lente and regular insulin was (apparently) dependent on the storage temperature of the insulin vials.

The present series of studies were undertaken to test the hypothesis that the storage temperature of in- sulin might play a role in influencing the pharmacokinetics and pharmacodynamics of the fast component of a mixture of intermediate-acting and regular insulin. For this purpose, lente and regular insulin on one occasion, and NPH and regular insulin on another occasion, stored either at $\sim 4^{\circ} \mathrm{C}$ or at $\sim 18^{\circ} \mathrm{C}$, were mixed in the same syringe and injected subcutaneously in subjects with Type 1 diabetes mellitus. Plasma free insulin concentration and the glucose infusion rate required to maintain euglycaemia were determined over the $16 \mathrm{~h}$ following the injection of the insulin mixtures.

\section{Subjects and methods}

Seven subjects $(4 \mathrm{M}, 3 \mathrm{~F})$ with Type 1 diabetes mellitus (plasma C-peptide less than $0.01 \mathrm{pmol} / 1$ after glucagon stimulation [15]), aged $27 \pm 3$ years (mean $\pm S E M$ ), with a body mass index of $22.03 \pm 0.57 \mathrm{~kg} / \mathrm{m}^{2}$, diabetes duration of $11 \pm 3$ years, were studied after giving fully informed consent, on two separate occasions, a 


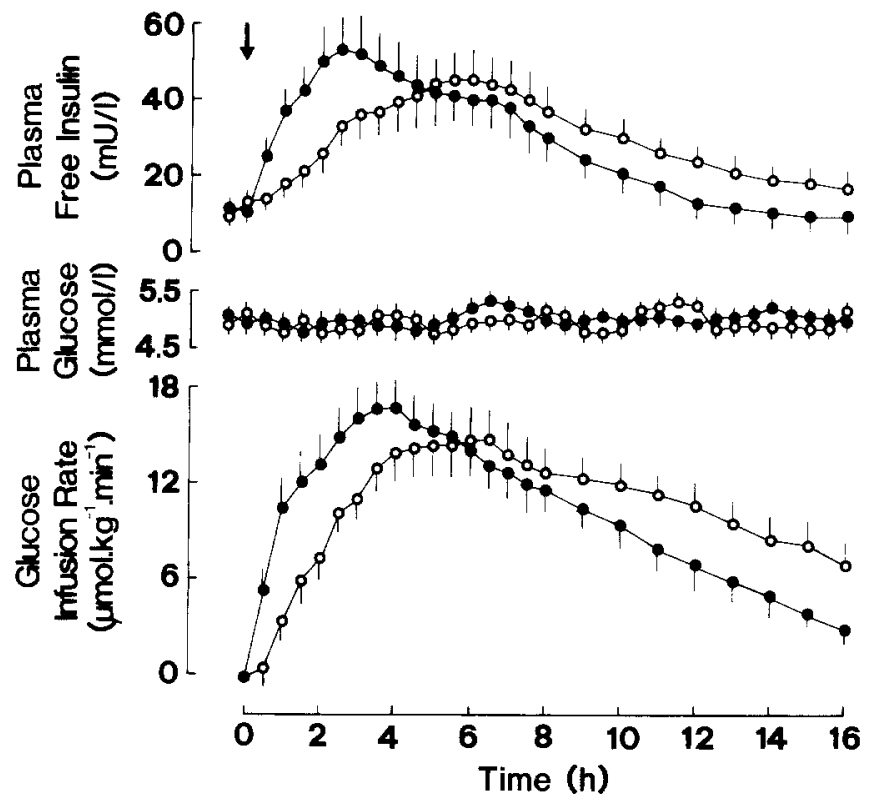

Fig. 1. Plasma free insulin and glucose infusion rates required to maintain euglycaemia (glucose clamp technique) after a subcutaneous injection (arrow, $\downarrow$ ) of an insulin mixture prepared from vials of regular (Actrapid $\mathrm{HM}, 0.11 \mathrm{U} / \mathrm{kg}$ ) and lente (Monotard $\mathrm{HM}$, $0.22 \mathrm{U} / \mathrm{kg})$ insulin stored refrigerated $\left(\sim 4^{\circ} \mathrm{C},-0\right)$ or at room temperature $\left(\sim 18^{\circ} \mathrm{C}, \bigcirc-\mathrm{O}\right)$ in 7 subjects with Type 1 (insulin-dependent) diabetes mellitus, studied in euglycaemia (variable intravenous insulin infusion until $0 \mathrm{~h}$ ). Values are mean \pm SEM

week apart. The diabetic subjects were on three daily subcutaneous injections of insulin (regular at breatfast and lunch; mixture of regular and lente at supper). Their $\mathrm{HbA}_{1 \mathrm{c}}$ was $6.8 \pm 0.2 \%$ as measured by high performance liquid chromatography [16] (in 15 non-diabetic subjects $6.1 \pm 0.7 \%$, mean $\pm \mathrm{SD}$ ). The last injection of intermediateacting insulin was given $36 \mathrm{~h}$ prior to the studies and only regular insulin was injected subcutaneously or intravenously thereafter. The subjects were admitted to the Clinical Research Center of the Istituto di Patologia Medica, University of Perugia, between 22.00 and 23.00 hours on the night preceding the study; they were placed at bed rest and maintained in the supine position throughout the experiments. An 18-gauge needle-catether was inserted into an antecubital vein of the forearm and kept patent with $0.9 \% \mathrm{NaCl}$ infusion $(0.5 \mathrm{ml} / \mathrm{min})$. This venous line was used for infusion of insulin and/or glucose. A 21-gauge butterfly-needle was inserted retrogradely into a dorsal vein of the contralateral hand which was kept at $70^{\circ} \mathrm{C}$ in a plexiglass hot box to obtain arterialised-venous blood [17]. At 23.00 hours an infusion of insulin (Actrapid HM, U-40, Novo Industri, Bagsvaerd, Denmark), diluted approximately at $1 \mathrm{U} / \mathrm{ml}$ in $0.9 \mathrm{NaCl}$ solution containing $0.5 \%$ human albumin (Immuno S.p. A., Pisa, Italy) was started by means of a Harvard pump (Harvard Apparatus, South Natick, Mass, USA) and continued until 08.00 hours the next morning. Insulin was infused at a variable rate based on the arterialised-venous plasma glucose concentration measured every 5-15 min, according to a previously described algorithm, in order to maintain a plasma glucose concentration of between 4.5 and $5.5 \mathrm{mmol} / 1$ [18]. At 08.00 hours the i.v. insulin infusion was stopped, and a mixture of lente intermediate-acting insulin (Monotard HM, Novo, $0.22 \mathrm{U} / \mathrm{kg}$ ) and regular insulin (Actrapid $\mathrm{HM}, 0.11 \mathrm{U} / \mathrm{kg}$ ) was injected within $1 \mathrm{~min}$ after its preparation into the abdominal wall ( $2 \mathrm{~cm}$ to the right or to the left of the umbilicus) using a $20 \mathrm{U} / 0.5 \mathrm{ml}$ B-D Plastipak Micro-fine III syringe. The subcutaneous injection was always performed by one of the authors, to keep inclination of needle $\left(45^{\circ}\right)$, depth, and time of injection as reproducible as possible. On one occasion, the insulin mixture was prepared from vials of regular and intermediate-acting insulin stored in the refrigerator $\left(\sim 4^{\circ} \mathrm{C}\right)$, whereas on the other occasion from insulin vials kept at room temperature $\left(\sim 18^{\circ} \mathrm{C}\right)$ overnight. The sequence of the studies was varied at random. Glucose was infused at a variable rate to maintain a plasma glucose concentration of between 4.5 and $5.5 \mathrm{mmol} / 1$ over the $16 \mathrm{~h}$ following the injection of the insulin mixture, as previously described [19].

Four out of the seven subjects underwent two additional studies, 1-2 months after completing the first two studies. The two additional studies were identical to the ones described above, but NPH insulin (Protaphane HM, Novo, $0.22 \mathrm{U} / \mathrm{kg}$ ) instead of lente was mixed with regular insulin (Actrapid $\mathrm{HM}, 0.11 \mathrm{U} / \mathrm{kg}$ ) from refrigerated insulin vials on one occasion, and from insulin vials stored at room temperature on the other occasion.

The zinc content of the lente insulin (Monotard HM) was $0.08 \mathrm{mg} / \mathrm{ml}$, and the protamine content of the NPH insulin was approximately $0.15 \mathrm{mg} / \mathrm{ml}$. The same batches of insulin were used for all studies. Plasma glucose was measured at bedside by means of a Beckman Glucose Analyzer (Beckman Instruments, Fullerton, Calif, USA). Plasma free insulin was measured as previously described [20] after polyethylene glycol extraction of plasma soon after blood sampling to remove insulin antibodies. Plasma C-peptide was measured by a previously described method [21].

\section{Statistical analysis}

Results (expressed as mean \pm SEM) were analysed by means of Anova [22].

\section{Results}

\section{Effects of storage temperature of insulin on pharmacokinetics and pharmacodynamics of the mixture lente and regular insulin (Fig.1)}

In these experiments, the mixture of lente and regular insulin was prepared from refrigerated insulin vials $\left(\sim 4^{\circ} \mathrm{C}\right)$ on one occasion, and from vials kept at room temperature $\left(\sim 18^{\circ} \mathrm{C}\right)$ overnight on the other occasion.

After injection of mixture of refrigerated insulins, plasma free insulin increased from $12 \pm 2 \mathrm{mU} / 1$ to a peak of $53 \pm 5 \mathrm{mU} / 1$ at $2.5 \pm 0.2 \mathrm{~h}$ and thereafter decreased to $30 \pm 6 \mathrm{mU} / 1$ at $8 \mathrm{~h}$; it was no longer different from baseline values at $16 \mathrm{~h}(10 \pm 2 \mathrm{mU} / \mathrm{l})$. Plasma glucose concentration during the $16 \mathrm{~h}$ clamp was $4.9 \pm 0.2 \mathrm{mmol} / 1$ (coefficient of variation, c.v., $3.7 \pm 0.2 \%)$. The glucose infusion rate required to maintain euglycaemia increased to a peak of $16.5 \pm 1.2 \mu \mathrm{mol} \cdot \mathrm{kg}^{-1} \cdot \mathrm{min}^{-1}$ at $3.2 \pm 0.3 \mathrm{~h}$, decreased to $11.8 \pm 0.9 \mu \mathrm{mol} \cdot \mathrm{kg}^{-1} \cdot \mathrm{min}^{-1}$ at $8 \mathrm{~h}$, and to $2.9 \pm 0.4 \mu \mathrm{mol} \cdot \mathrm{kg}^{-1} \cdot \mathrm{min}^{-1}$ at $16 \mathrm{~h}$.

After injection of non-refrigerated insulin mixtures, the initial increase in plasma free insulin was slower as compared to that observed with the mixture of refrigerated insulins, with a later $(6 \pm 0.3 \mathrm{~h})$ and lower peak $(45 \pm 6 \mathrm{mU} / 1)$ as compared to that observed with the mixture of refrigerated insulins $(p<0.05)$. However, from 8 through $16 \mathrm{~h}$, the mean plasma free insulin concentration was greater than that following injection of the mixture of refrigerated insulins $(22 \pm 4 \mathrm{mU} / 1$ ver- 


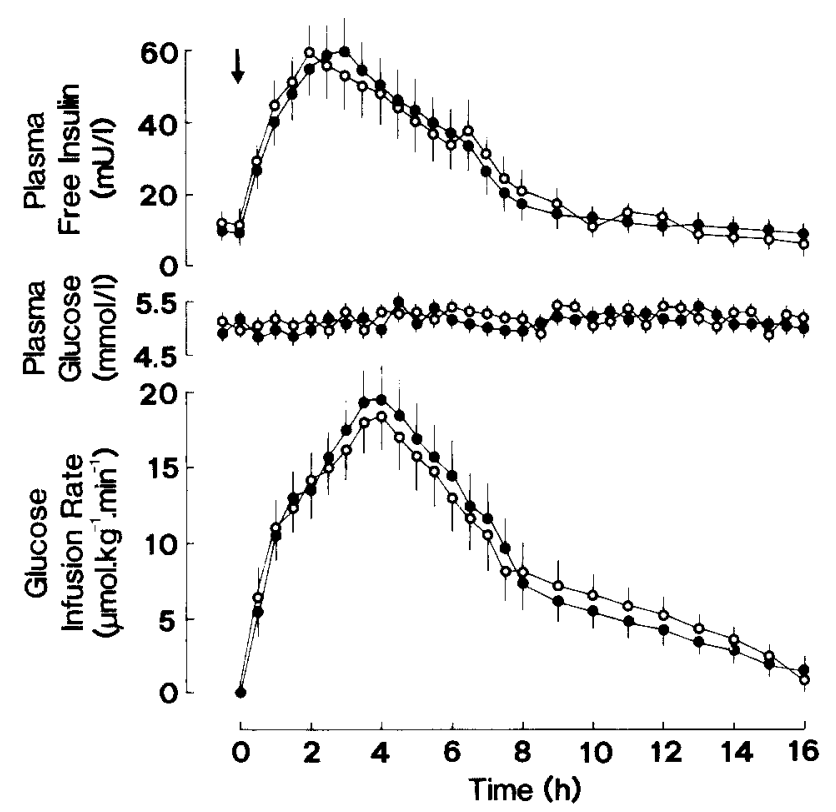

Fig. 2. Plasma free insulin and glucose infusion rates required to maintain euglycaemia (glucose clamp technique) after a subcutaneous injection (arrow, $\downarrow$ ) of an insulin mixture prepared from vials of regular (Actrapid HM, 0.11 U/kg) and $\mathrm{NPH}$ (Protaphane $\mathrm{HM}$, $0.22 \mathrm{U} / \mathrm{kg})$ insulin stored refrigerated $\left(\sim 4^{\circ} \mathrm{C}, \longrightarrow\right.$ ) or at room temperature $\left(\sim 18^{\circ} \mathrm{C}, \mathrm{O}-\mathrm{O}\right)$ in 7 subjects with Type 1 diabetes mellitus, studied in euglycaemia (variable intravenous infusion until $0 \mathrm{~h}$ ). Values are mean $\pm S E M$

sus $14 \pm 3 \mathrm{mU} / 1, p<0.05$ ). Plasma glucose concentration was $5.1 \pm 0.3 \mathrm{mmol} / \mathrm{l}$ during the $16 \mathrm{~h}$ clamp (c.v. $4.1 \pm 0.4 \%$ ). The increase in glucose infusion rate required to maintain euglycaemia was initially slower as compared to that following injection of the mixture of refrigerated insulins, with a later $(6 \pm 0.4 \mathrm{~h})$ and lower peak $\left(14.5 \pm 0.9 \mu \mathrm{mol} \cdot \mathrm{kg}^{-1} \cdot \mathrm{min}^{-1}\right)$ as compared to that observed after injection of mixture of refrigerated insulin $(p<0.05)$. However, from 8 through $16 \mathrm{~h}$, the mean glucose infusion rate was greater with the mixture of non-refrigerated than refrigerated insulin $\left(10.03 \pm 0.9 \mu \mathrm{mol} \cdot \mathrm{kg}^{-1} \cdot \mathrm{min}^{-1} \quad\right.$ versus $\quad 8.03 \pm 0.8$ $\left.\mu \mathrm{mol} \cdot \mathrm{kg}^{-1} \cdot \min ^{-1}, p<0.05\right)$.

There were no significant differences between the areas under curves of plasma free insulin $\left(18.6 \pm 2.5 \mathrm{mU} \cdot 1^{-1} \cdot 16 \mathrm{~h}^{-1}\right.$ and $19.3 \pm 3.4 \mathrm{mU} \cdot 1^{-1}$. $\left.16 \mathrm{~h}^{-1}\right)$ and glucose infusion rate $(10.9 \pm 1.1$ $\mu \mathrm{mol} \cdot \mathrm{kg}^{-1} \cdot 16 \mathrm{~h}^{-1}$ and $11.1 \pm 0.7 \mu \mathrm{mol} \cdot \mathrm{kg}^{-1} \cdot 16 \mathrm{~h}^{-1}$ ) after injection of mixture of refrigerated and nonrefrigerated insulin respectively.

\section{Effects of storage temperature of insulin} on pharmacokinetics and pharmacodynamics of the mixture NPH and regular insulin (Fig. 2)

After injection of the mixture of NPH and regular insulin, the plasma insulin concentration and the glucose infusion rates required to maintain euglycaemia over the following $16 \mathrm{~h}$ were no different than when the mixture was prepared from refrigerated insulin, as compared to when the mixture was prepared from non-refrigerated insulin. Thus, the storage temperature of NPH insulin had no effect on pharmacokinetics and pharmacodynamics of the mixture of NPH and regular insulin.

\section{Discussion}

The present study demonstrates that the storage temperature of insulin influences the pharmacokinetics and the pharmacodynamics of a mixture of lente and regular insulin injected subcutaneously in subjects with Type 1 diabetes mellitus. Compared to a mixture of refrigerated insulins, the injection of a mixture of non-refrigerated insulins $\left(\sim 18^{\circ} \mathrm{C}\right)$ resulted initially in a partial loss of activity of the fast component, but later in a greater activity of the slow component. On the other hand, the storage temperature of insulin had no effect on the activity of the mixture of NPH and regular insulin.

Several [7, 23], although not all $[24,25]$ in vitro studies - but invariably all in vivo studies in nondiabetic $[2-4]$ as well as in diabetic subjects $[5-7,11]-$ have demonstrated that mixing lente with regular insulin causes a significant loss of activity in the fast component of the mixture, a phenomenon not observed after mixing NPH with regular insulin. In vivo studies indicate that such a phenomenon is exaggerated by the relatively high proportion of lente insulin [2], by the prolongation of the time interval between preparation and injection of the insulin mixture [3, 4], and also apparently by insulin species, because it is more evident with semi-synthetic human than with porcine monocomponent insulin [26, 27]. The present study demonstrates that another factor, i.e. the storage temperature of insulin vials from which the mixture is prepared, plays a critical role.

In the present study, the storage temperature of insulin influenced also the activity of the slow component of the lente/regular insulin mixture, a finding not shown in previous studies (with one exception, [11]), which were already terminated $4-8 \mathrm{~h}$ after the injection of an insulin mixture. In the present study, the plasma free insulin concentration, as well as glucose infusion rate required to maintain euglycaemia from 8 to $16 \mathrm{~h}$ after the injection of mixture lente/regular were approximately $40 \%$ lower when refrigerated insulins were mixed, as compared to the mixture of non-refrigerated insulins.

The findings of the present study might have a relevant implication for the treatment of Type 1 diabetes mellitus. Unless the storage temperature of lente insulin is strictly standardised, the bio-availability of insulin after a preprandial injection of a lente/regular insulin mixture might vary from time to time; a phenomenon which would contribute to fluctuations in 
blood glucose control. Since the storage temperature of lente affects the pharmacokinetics of both the fast and the slow components of the mixture with regular insulin, glycaemic fluctuations might occur both soon after the meal and later in the interprandial fasting periods.

The mechanism(s) by which storage temperature of insulin influence(s) the pharmacokinetics of both the fast and the slow components of the mixture lente/regular insulin remain(s) a matter of speculation. Theoretically, it could be a direct mechanism, i.e., room temperature might accelerate the interaction between the excess of zinc in the acetate buffer of the lente insulin (concentration 2.73\%) and the regular insulin of the mixture. Such binding of regular insulin by the zinc would cause the loss of activity of the fast component of the mixture. In a later phase, the regular insulin initially bound would be released as if it were lente insulin, and would contribute to the greater plasma free insulin concentration observed in the present study from $8-16 \mathrm{~h}$ after the subcutaneous injection of the mixture. However, the effect of temperature could also be indirect, i.e. room temperature could shift zinc molecules from the crystals of lente insulin into the acetate buffer, and such an increased availability of zinc would in turn interact with regular insulin, as hypothesized above.

From the results of previous studies [1-7] and the present study it could be concluded that, unless the vials of lente and regular insulin are kept strictly refrigerated, lente insulin should not be mixed with regular insulin. Theoretically, the problem of poor miscibility of lente and regular insulin might be overcome by giving separate injections. Such an approach, however, seems quite impractical. Apparently, sequential subcutaneous injections of lente and regular insulin with separate syringes but through the same needle seem to provide results similar to those of separate injections [28]. Alternatively, NPH instead of lente insulin may be safely mixed with regular insulin in the same syringe.

In summary, the storage temperature of insulin affects the pharmacokinetics and the pharmacodynamics of the mixture of lente/regular insulin. Mixing lente and regular insulin stored at room temperature causes a significant loss of the fast component, but an increased activity of the slow component. Injections of mixtures of lente/regular insulin prepared regardless of temperature of storage may cause erratic results in the pharmacokinetics of both fast and slow components of the mixture, and could contribute to the instability of blood glucose control in insulin-treated diabetic subjects.

Acknowledgements. The editorial help of Ms. P. Boyce is gratefully acknowledged. This work was supported by the University of Perugia (quota 60\%), by grant of the Umbria Region (1987), and by grant 88.00444.04 of the National Research Council (C. N. R.).

\section{References}

1. Schlichtkrull J (1977) The absorption of insulin. Acta Paediatr Scand 270 (Suppl): 97-102

2. Galloway JA, Spradlin CT, Nelson RL, Wentworth SM, Davidson JA, Swarner JL (1981) Factors influencing the absorption, serum insulin concentration, and blood glucose responses after injections of regular insulin and various insulin mixtures. Diabetes Care 4: 366-376

3. Berger M, Cuppers HJ, Hegner H, Jorgens V, Berchtold P (1982) Absorption kinetics and biological effects of subcutaneously injected insulin preparations. Diabetes Care 5: 77-91

4. Heine RJ, Bilo HJG, Fonk T, van der Veen EA, von der Mer J (1984) Absorption kinetics and action profiles of mixtures of short and intermediate-acting insulins. Diabetologia 27: 558-562

5. Colagiuri S, Villabolos S (1986) Assessing effect of mixing insulins by glucose clamp technique in subjects with diabetes mellitus. Diabetes Care 9: 579-586

6. Forlani G, Santacroce G, Ciavarella A, Capelli M, Mattioli L, Vannini P (1986) Effects of mixing short- and intermediateacting insulins on absorption course and biologic effect of shortacting preparation. Diabetes Care 9: 587-590

7. Olsson PO, Arnqvist H, von Schenck H (1987) Miscibility of human semisynthetic regular and lente insulin and human biosynthetic regular and NPH insulin. Diabetes Care 10: 473-477

8. Muhlhauser I, Broermann C, Tsotsalas M, Berger M (1984) Miscibility of human and bovine ultralente insulin with soluble insulin. Br Med J 289: 1656-1657

9. Heine RJ, Bilo HJG, Sikkenk AC, van der Veen EA (1985) Mixing short and intermediate acting insulins in the syringe: effect on postprandial blood glucose concentrations in type 1 diabetics. Br Med J 290: 204-205

10. Goicolea I, Quiroga A, Vazquez JA (1987) The effect of insulin mixtures in type 1 diabetics: influence of the intermediate acting insulin on the action of short acting insulin. Diabete Metabolisme 13: $467-470$

11. Best JD, Ley CJ, Strauss BJG, Alford FP, Aitken PM (1987) The clinical effects of mixing short- and intermediate-acting insulins in the treatment of non-insulin-dependent diabetes. Med J Austr 146: 621-627

12. Kolendorf K, Boisen J, Deckert T (1983) Absorption and miscibility of regular porcine insulin after subcutaneous injection in insulin-treated diabetic patients. Diabetes Care 6:6-9

13. Deckert T (1980) Intermediate acting insulin preparations: NPH and Lente. Diabetes Care 3: 623-626

14. Binder C, Lauritzen T, Faber O, Pramming S (1984) Insulin pharmacokinetics. Diabetes Care 3: 188-199

15. Faber O, Binder C (1977) C-peptide response to glucagon: a test for the residual B-cell function in diabetes mellitus. Diabetes 26: 605-610

16. Naka K, Yamazaki K, Yamamoto H (1981) Development of glycosylated hemoglobin A1c Auto-Analyzer. Jpn J Clin Lab Automation 6 [Suppl]: 1-2

17. McGuire E, Helderman J, Tobin R, Andres R, Berman M (1976) Effects of arterial versus venous sampling on analysis of glucose kinetics in man. J Appl Physiol 41: 565-573

18. De Feo P, Perriello G, Ventura MM, Calcinaro F, Basta G, Lolli C, Cruciani C, Dell'Olio A, Santeusanio F, Brunetti P, Bolli GB (1986) Studies on overnight insulin requirements and metabolic clearance rate of insulin in normal and diabetic man: relevance to the pathogenesis of the dawn phenomenon. Diabetologia 29: $475-480$

19. Bolli G, De Feo P, Perriello G, De Cosmo S, Compagnucci P, Santeusanio F, Brunetti P, Unger RH (1984) Mechanisms of glucagon secretion during insulin-induced hypoglycemia in man: role of the betacell and arterial hyperinsulinemia. J Clin Invest 73: 917-922

20. Kuzuya H, Blix PM, Horwitz DL, Steiner DF, Rubenstein AH (1977) Determination of free and total insulin and C-peptide in insulin-treated diabetics. Diabetes 26: 22-29 
21. Faber O, Binder C, Markussen J, Heding L, Naithani V, Kuzuya H, Blix P, Horwitz D, Rubenstein A (1978) Characterization of seven C-peptide antisera. Diabetes 27 [Suppl. 1]: 170-177

22. Zar J (1984) Biostatistic Analysis. Prentice Hall, Englewood Cliffs, NJ

23. Grootendorst BC, Jonkers JR, Kruit I (1983) The miscibility of short acting insulins with depot insulins. An in vitro study Pharm Week 118: 746-751

24. Galloway JA, Spradlin T, Jackson RL, Otto CD, Bechte LD (1982) Mixtures of intermediate-acting insulin (NPH and lente) with regular insulin: a update. In: Skyler $\mathbf{J}$ (ed) Insulin update. Excerpta Medica, Amsterdam, p 11-120

25. Nolte MS, Poon V, Grodsky GM, Forsham PH, Karam JH (1983) Reduced solubility of short-acting soluble insulins when mixed with longer-acting insulins. Diabetes 32: 1177-1181

26. Tsotsalas M, Muhlhauser I (1985) Miscibility of human lente insulin with soluble insulin. Diabetologia 28: 252

27. Berger M (1985) Pharmacokinetics of subcutaneously injected insulin: the miscibility of short and long-acting insulin prepara- tions. In: Crepaldi G, Tiengo A, Baggio G (eds) Diabetes, Obesity and Hyperlipemias, Vol 3. Excerpta Medica, Amsterdam, p 427-431

28. Bilo HJ, Sikkenk AC, van der Meer J, van der Veen EA (1987) Absorption kinetics and action profiles after sequential subcutaneous administration of human soluble and lente insulin through one needle. Diabetes Care 10: 466-469

Received: 26 May 1988

and in revised form: 1 September 1988

Prof. G. B. Bolli

Istituto di Patologia Medica

dell'Università

Via E. Dal Pozzo

I-06100 Perugia

Italy 